PROBIOTICS

\title{
Modulation of human dendritic cell phenotype and function by probiotic bacteria
}

\author{
A L Hart, K Lammers, P Brigidi, B Vitali, F Rizzello, P Gionchetti, M Campieri, M A Kamm, \\ S C Knight, A J Stagg
}

Background: "Probiotic" bacteria are effective in treating some inflammatory bowel diseases. However which bacteria confer benefit and mechanisms of action remain poorly defined. Dendritic cells, which are pivotal in early bacterial recognition, tolerance induction, and shaping of T cell responses, may be central in mediating the effects of these bacteria.

See end of article for authors' affiliations .....................

Correspondence to: Dr A J Stagg, Antigen Presentation Research Group, Faculty of Medicine Imperial College London, Northwick Park Campus, Watford Road, Harrow, Middlesex HA 1 3UJ, UK; a.stagg@ imperial.ac.uk

Accepted for publication 15 April 2004
Aims: To assess effects of different probiotic bacteria on dendritic cell function.

Methods: Human intestinal lamina propria mononuclear cells, whole blood, or an enriched blood dendritic cell population were cultured with cell wall components of the eight bacterial strains in the probiotic preparation VSL\#3 (four lactobacilli, three bifidobacteria, and one streptococcal strains). Dendritic cells were identified and changes in dendritic cell maturation/costimulatory markers and cytokine production in response to probiotic bacteria were analysed by multicolour flow cytometry, in addition to subsequent effects on $T$ cell polarisation.

Results: VSL\#3 was a potent inducer of IL-10 by dendritic cells from blood and intestinal tissue, and inhibited generation of Th1 cells. Individual strains within VSL\#3 displayed distinct immunomodulatory effects on dendritic cells; the most marked anti-inflammatory effects were produced by bifidobacteria strains which upregulated IL-10 production by dendritic cells, decreased expression of the costimulatory molecule CD80, and decreased interferon- $\gamma$ production by T cells. VSL\#3 diminished proinflammatory effects of LPS by decreasing LPS induced production of IL- 12 while maintaining IL-10 production.

Conclusions: Probiotic bacteria differ in their immunomodulatory activity and influence polarisation of immune responses at the earliest stage of antigen presentation by dendritic cells.
$\mathrm{T}$ he intestinal immune system forms the largest part of the immune system. It interacts with a complex antigenic load in the form of food antigens, commensal bacteria, and occasional pathogens. Dendritic cells (DC) are pivotal in earliest bacterial recognition and in shaping $\mathrm{T}$ cell responses. In the intestine DC have specialised functions most likely as a result of their close proximity with the external environment. ${ }^{1}$ They are involved in generating regulatory $\mathrm{T}$ cells and IgA producing B cells through production of cytokines such as IL-10 and TGF $\beta .^{2-4}$ They contribute to oral tolerance induction $^{5}$ and determine homing of lymphocytes back into intestinal tissue. ${ }^{6}$ Intestinal DC interact directly with luminal bacteria by passing their dendrites between epithelial tight junctions into the gut lumen ${ }^{7}$ and indirectly with bacteria that have gained access via $M$ cells.

Microbial products play a key role in regulating DC responses. DC interact with microbes using pattern recognition receptors, including toll-like receptors (TLR). Using such a system, DC distinguish between and mount different responses to even closely related organisms..$^{8-11}$ For example, lipopolysaccharide (LPS) from $E$ coli interacts with TLR4 and generates a Thl response, whereas LPS from Porphyromonas gingivalis interacts with TLR2 and generates a Th2 response. ${ }^{11}{ }^{12}$ This ability to respond appropriately to different microbial products is of particular importance in the gastrointestinal tract, where a diverse microbial flora lies close to DC.

Dendritic cells sense antigen in tissues before migrating to draining lymph nodes, where they have the unique ability to activate and influence functional differentiation of naïve $T$ cells. Signals from DC can determine whether tolerance or an active immune response occurs to a particular antigen ${ }^{13}{ }^{14}$ and furthermore influence whether a Th1 or Th2 immune response predominates. DC subtype, whether CDllc+ (myeloid) or CDllc- (plasmacytoid/lymphoid), maturation status, and cytokine production contribute to the type of $\mathrm{T}$ cell response. For example, DC upregulate the costimulatory molecules, CD80 and CD86, and produce IL-12 which contributes to a Thl response. ${ }^{15}$ DC also produce IL-10 and IL-4 which promote the generation of a Th2 response or regulatory T cells. ${ }^{3}{ }^{16}$

Some commensal organisms from intestinal flora have health-promoting properties and are used in probiotic preparations. The probiotic mixture, VSL\#3 (VSL\#3 Pharmaceuticals, Fort Lauderdale, FL, USA), which contains eight different bacterial strains (four lactobacilli, three bifidobacteria, and one Streptococcus thermophilus subsp Salivarius) is beneficial in treating some inflammatory bowel diseases (IBD). Controlled clinical trials have shown that VSL\#3 maintains remission of pouchitis ${ }^{17}$ and prevents onset of pouchitis after pouch formation. ${ }^{18}$ The non-pathogenic $E$ coli Nissle strain is beneficial in maintenance treatment of ulcerative colitis. ${ }^{19} 20$

Central to the mechanism of action of probiotics is their modulation of host immune response. An increased understanding of the effects of clinically active probiotic bacteria on the immune system may enable refinement of probiotic treatments for use under defined disease circumstances and enhance our knowledge of immune homeostasis in the

Abbreviations: DC, dendritic cell; ELISA, enzyme linked immunosorbent assay; IBD, inflammatory bowel diseases; LPDC, lamina propria DC LPS, lipopolysaccharide; PBMC, peripheral blood mononuclear cell; PE, phycoerythrin; TLR, toll-like receptor. 
specialised environment of the intestine. We hypothesised that probiotic organisms exert modulatory activity on the host immune system via DC. The objective was to investigate effects of combined and individual probiotic strains and LPS on the phenotype and function of both blood and intestinal DC derived from the colonic lamina propria in order to establish which organisms may confer benefits at this early stage in antigen presentation. Cross regulatory effects between microbial products inducing polarised responses were also assessed. Furthermore, the subsequent effect of DC exposed to probiotic bacteria on polarisation of the $\mathrm{T}$ cell response was examined.

\section{METHODS \\ Preparation of bacterial fractions}

The bacterial fractions investigated are shown in table 1. Bacterial fractions were prepared as described in Lammers, et al. ${ }^{21}$ The VSL\#3 Lactobacillus and Bifidobacterium strains were grown anaerobically at $37^{\circ} \mathrm{C}$ in MRS medium (Difco, USA) supplemented with $0.05 \%$ L-cysteine. The VSL\#3 Streptococcus salivarius subsp thermophilus was grown anaerobically in M17 medium (Difco, USA). Streptococcus faecium was also grown anaerobically in M17 medium. Non-pathogenic Escherichia coli Nissle strain 1917 was grown aerobically in LB (Difco, USA). Mid log cultures were collected by centrifugation and subsequently sonicated (Branson Sonifier W-250, Heinemann, Schwäbisch, Germany) at a power level 5-6 at $30 \%$ duty for five minutes. Sonicates were centrifuged and bacterial debris fractions were collected. In assays where all strains were assessed in combination, sonicates of individual strains were pooled.

\section{Monoclonal antibodies}

The antibodies used were: CDllc-FITC (KB90) (Dako, Cambridgeshire, UK); CD3-PC5 (UCHT-1), CD14-PC5 (MIP9), CD16-PC5 (B73.1), CD19-PC5 (4G7), CD56-PC5 (N901), and CD8-PC5 (B9.11) (Beckman Coulter, High Wycombe, UK); CD34-CyChrome (581), CD86-PE (BU63), CD40-PE (LOB7/6) (Serotec, Oxford, UK); HLA-DR-APC (G46-6), CD80-PE (L307.4), CD83-PE (HB15e), CD3-FITC (UCHT1), CD69-PE (FN50), and CD8-FITC/PE/APC (SK1) (BD Biosciences Pharmingen, Oxford, UK). Isotype matched controls were obtained from the same manufacturers. Intracellular cytokine staining used: IFN- $\gamma$-PE (clone D9D10), IFN- $\gamma$-FITC (clone B-Bl), IL-10-PE (clone JES39D7) (Serotec, Oxford, UK), and IL-12(p40)-PE (clone C11.5) and IL-4 PE (3007.11) (BD Biosciences Pharmingen, UK). Neutralising anti-IL-10 antibody (Clone 9D7) was purchased from Endogen (Cheshire, UK).

\section{Table 1 Bacterial strains}

Bacterial strains in VSL\#3 (VSL\#3 Pharmaceuticals, Gaithersburg, MD, USA)

Lactobacillus acidophilus MB443

Lactobacillus delbrueckii subsp bulgaricus MB 453

Lactobacillus casei MB 451

Lactobacillus plantarum MB452

Bifidobacteria longum Y10

Bifidobacteria infantis $Y 1$

Bifidobacteria breve Y8

Streptococcus salivarius subsp thermophilus MB455

Other bacterial strains used

Escherichia coli non-pathogenic Nissle strain 1917 (Mutaflor-

Ardeypharm, Herdecke, Germany)

Lipopolysaccharide from $E$ coli 026:B6

Streptococcus faecium MB454

\section{Blood dendritic cells}

Blood was collected from healthy volunteers into lithium heparin and incubated with culture medium alone (RPMI1640 Dutch Modification, Sigma-Aldrich, UK), varying concentrations of bacterial cell debris fractions $\left(10^{6}-\right.$ $\left.10^{9} \mathrm{CFU} / \mathrm{ml}\right)$, LPS $(1 \mu \mathrm{g} / \mathrm{ml})$ or control medium alone for four or 16 hours at $37^{\circ} \mathrm{C}$ in $5 \% \mathrm{CO}_{2}$. An enriched DC population was prepared from peripheral blood mononuclear cells (PBMC). PBMC were prepared by centrifugation of blood over a Ficoll-Paque gradient (Amersham Biosciences, UK) and cultured overnight in complete medium (RPMI1640 Dutch Modification supplemented with 10\% FCS, 2 mM L-glutamine, $100 \mu \mathrm{g} / \mathrm{ml}$ streptomycin, $100 \mathrm{U} / \mathrm{ml}$ penicillin) at $37^{\circ} \mathrm{C}$ in $5 \% \mathrm{CO}_{2}$. Non-adherent DC rich low density cells were separated on hypertonic metrizamide $(14.5 \% \mathrm{w} / \mathrm{v})$ by centrifugation and incubated at $37^{\circ} \mathrm{C}$ in $5 \% \mathrm{CO}_{2}$ for four hours with bacterial cell debris fractions, LPS or control medium alone.

\section{Human colonic lamina propria dendritic cells}

Human intestinal biopsies were obtained at routine colonoscopy from patients with macroscopically and histologically normal intestine who had been referred with rectal bleeding or altered bowel habit. Informed consent was obtained and the protocol was approved by the local ethics committee. At least 10 mucosal biopsies (approximately $60 \mathrm{mg}$ ) were taken per patient. ${ }^{22}$ Collagenase digestion of tissue was performed using collagenase D (Roche Diagnostics, Mannheim, Germany) in $10 \mathrm{ml}$ RPMI-1640 HEPES (Sigma Aldrich Co Ltd, Irvine, UK), $2 \%$ FCS and $2 \mu \mathrm{M}$ DNase I (Boehringer, Mannheim, Germany). Lamina propria mononuclear cells $\left(2.5 \times 10^{5}\right.$ cells per well, Falcon 96 well, U bottom $)$ were cultured for four hours at $37^{\circ} \mathrm{C}$ in $5 \% \mathrm{CO}_{2}$ with bacterial cell debris fractions, LPS, or control medium alone.

\section{Cytokine production by DC}

Cytokine production by DC subsets was assessed by intracellular staining in whole blood cultures, enriched DC cultures, and intestinal cell cultures in a modification of the method described by North et al. ${ }^{23}$ Comparison of paired cultures, one incubated with monensin $(3 \mu \mathrm{mol} / \mathrm{l})$ to maintain cytokine within the cells and the other incubated without monensin allowed assessment of cytokine production. In whole blood assays, red cells were lysed with $500 \mu \mathrm{l}$ Optilyse C (Beckham Coulter, High Wycombe, UK) for 15 minutes at room temperature. Cells were fixed with Leucoperm A ( $100 \mu \mathrm{l}$, Serotec) and permeabilised with Leucoperm B (100 $\mu \mathrm{l}$, Serotec). The cytokine antibody $(5 \mu \mathrm{l})$ was added for 30 minutes. Blocking experiments were performed with an unlabelled antibody of an identical clone to the one used for cytokine staining and an irrelevant antibody to assess specificity of binding.

\section{Enzyme linked immunosorbent assay (ELISA)}

Concentrations of IL-10 in culture supernatants from enriched DC populations incubated with bacterial fractions were measured by ELISA using a paired antibody kit (Endogen, UK). IL-10 coating antibody was used at $2 \mu \mathrm{g} / \mathrm{ml}$ and biotinylated antihuman IL-10 detecting antibody at $0.75 \mu \mathrm{g} / \mathrm{ml}$. Absorbance values were read at $450 \mathrm{~nm}$ on an ELISA plate reader. The assay's detection limit was $36 \mathrm{pg}$ IL-10/ml.

\section{Differentiation of $\mathrm{T}$ cells after exposure to bacterial products}

Two methods were used to assess effects of exposure to bacterial products on the subsequent $\mathrm{T}$ cell response. Naïve CD4+ T cells were prepared from PBMC by negative selection to a purity $>87 \%$ using a StemSep kit ( StemCell Technologies 

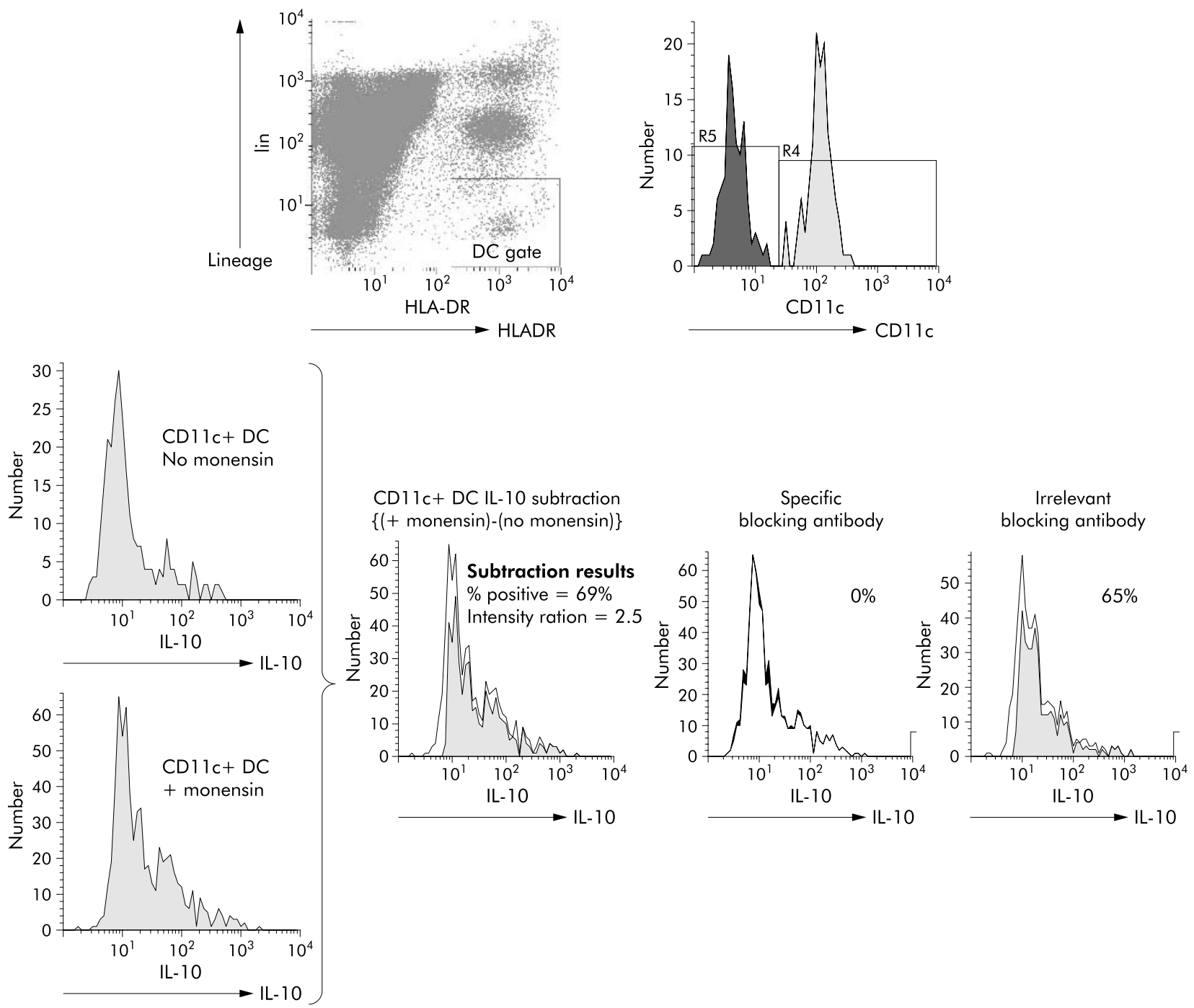

Figure 1 Cytokine production by blood dendritic cells. Dendritic cells (DC) were identified by multicolour flow cytometry as an HLA-DR+ lineage negative (CD3-, CD14-, CD16-, CD19-, CD34-, and CD56-) population. Within this DC gate, CD11c+ and CD11c- DC subsets were identified. The cytokine production by these $D C$ subsets was assessed by intracellular cytokine staining and super-enhanced $D_{\max }$ normalised subtraction. One parameter histograms for the intracellular staining of IL-10 with and without added monensin are shown. In this example, cultures were stimulated with VSL\#3 probiotic bacteria. Intracellular cytokine production was determined by subtracting labelling of the sample without monensin from labelling of the sample with monensin using WinList software. In the histograms with subtraction percentages, the outline of the histogram indicates staining of monensin treated cells and the shaded area represents the proportion of cytokine positive cells after the subtraction. Cytokine detection was competitively inhibited by unlabelled antibody of the same clone as that used for cytokine detection, but not by unlabelled antibody of irrelevant specificity.

Inc, Vancouver, Canada). DC rich low density cells $\left(8 \times 10^{3}\right.$ cells per well) exposed to control medium alone, VSL\#3 $\left(10^{8} \mathrm{CFU} / \mathrm{ml}\right)$ or LPS $(1 \mu \mathrm{g} / \mathrm{ml})$ were co-cultured with $4 \times 10^{5}$ per well allogeneic naïve CD4+ $\mathrm{T}$ cells for six days. At this time point, cultures were supplemented with $30 \mathrm{U} / \mathrm{ml}$ recombinant IL-2. After a further six days, cells were cultured for four hours in complete medium with phorbol-myrsitateacetate (PMA-16.2 nmol/l), ionomycin $(2 \mu \mathrm{mol} / \mathrm{l})$, and monensin $(3 \mu \mathrm{mol} / \mathrm{l})$ or monensin alone. Cytokine production was assessed by intracellular staining. ${ }^{23}$

To assess whether prior exposure to bacterial products influences IFN- $\gamma$ production by polyclonally activated T cells, blood was incubated with varying concentrations of bacterial fractions in culture medium for 14 hours at $37^{\circ} \mathrm{C}$ in $5 \% \mathrm{CO}_{2}$. To assess the role of IL-10, a neutralising anti-IL-10 antibody or an isotype matched control antibody was added to some cultures $(20 \mu \mathrm{g} / \mathrm{ml})$. Subsequently, cultures were activated with phorbol-myrsitate-acetate (PMA) and ionomycin, in addition to monensin, or treated with monensin alone for a further four hours at $37^{\circ} \mathrm{C}$ in $5 \% \mathrm{CO}_{2}$. Cytokine production was assessed by intracellular staining.

\section{Data and statistical analysis}

Data were acquired uncompensated using a FACSCalibur (Becton Dickinson) flow cytometer. Objective compensation was applied using the Compensation Toolbox within the WinList Version 5.0 flow cytometry software (Verity, Topsham, ME USA). The proportion of cytokine positive cells was determined by subtraction of histograms using the super-enhanced $\mathrm{D}_{\max }(\mathrm{SED})$ normalised subtraction facility in WinList. Staining of cells cultured in the absence of monensin was subtracted from staining of cells cultured in the presence of monensin, giving a measure of ongoing cytokine production. ${ }^{24}$ This technique allows positive cells to be resolved in situations where distribution histograms overlap. The use of the same antibody to label cells from 

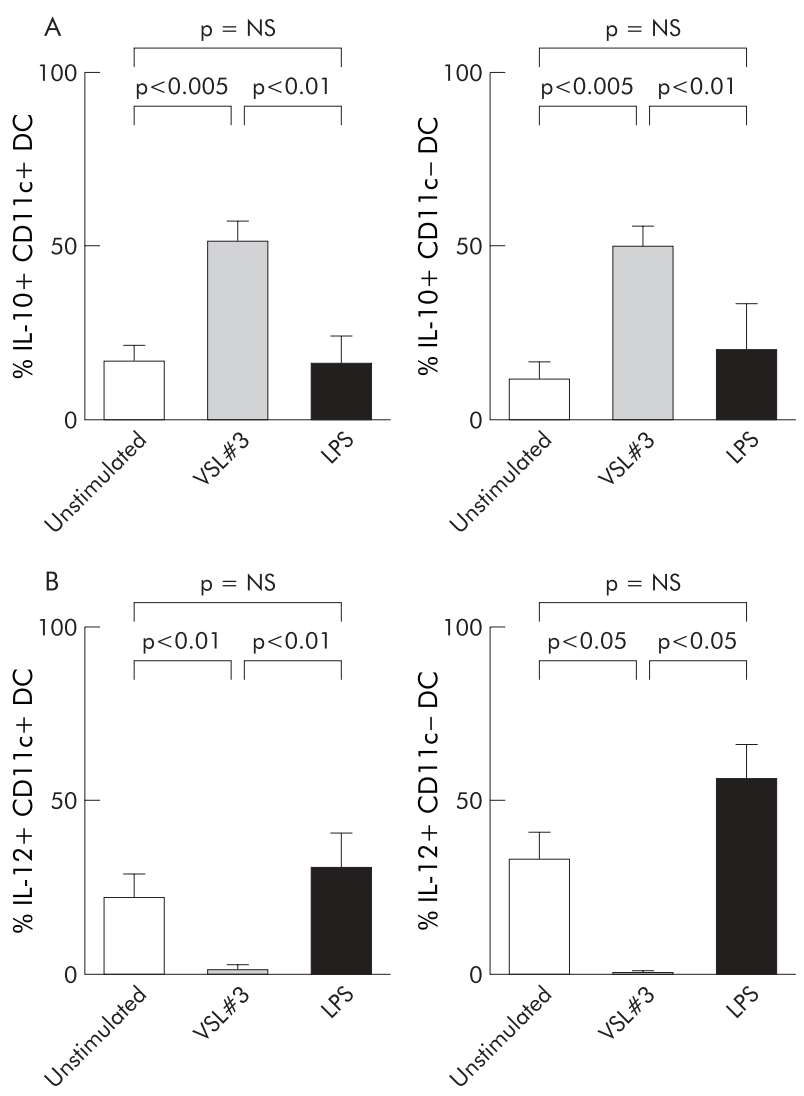

Figure 2 Enhanced IL-10 production and decreased IL-12 production by blood DC in the presence of probiotic bacteria (VSL\#3). Whole blood was incubated with control medium alone, VSL\#3 probiotic bacteria (at a dose equivalent to $10^{8} \mathrm{CFU} / \mathrm{ml}$ ) or LPS $(1 \mathrm{\mu g} / \mathrm{ml})$ for four hours and (A) IL-10 production and (B) IL-12 production was assessed by intracellular cytokine staining. The proportion of cytokine staining CDIlc+ and CDIlc- DC is shown (mean (SEM), $\mathrm{n}=9-13$ ).

both monensin treated and untreated cultures gives this technique a high degree of sensitivity for detecting small changes in antibody binding. Specificity of antibody labelling was confirmed in competition experiments with unlabelled antibodies. Absolute cell counts were obtained by reference to counts of Flow-Count fluorospheres acquired simultaneously. Two tailed $t$ tests were used to compare proportions and absolute numbers of cells. Data were paired where appropriate. Values of $\mathrm{p}<0.05$ were regarded as significant.

\section{RESULTS}

\section{Identification of dendritic cells}

Blood DC were identified as HLA-DR+ lineage negative (CD3-, CD14-, CD16-, CD19-, CD34-, CD56-) cells. Within this gate, CDllc+ (myeloid) and CDllc- (plasmacytoid) DC populations were present. Cytokine production by CDllct and CDllc- DC populations was assessed by intracellular staining. Cytokine detection was competitively inhibited by unlabelled antibody of the same clone as that used for cytokine detection, but not by unlabelled antibody of irrelevant specificity (fig 1).

\section{VSL\#3 upregulates IL-10 and downregulates IL- 12 production by blood and colonic lamina propria dendritic cells}

The probiotic combination VSL\#3 at a dose equivalent to $10^{8} \mathrm{CFU} / \mathrm{ml}$ upregulated IL-10 production and decreased IL-12 production by CDllc+ and CDllc- DC (fig 2). This increase in IL-10 production in the presence of VSL\#3 was

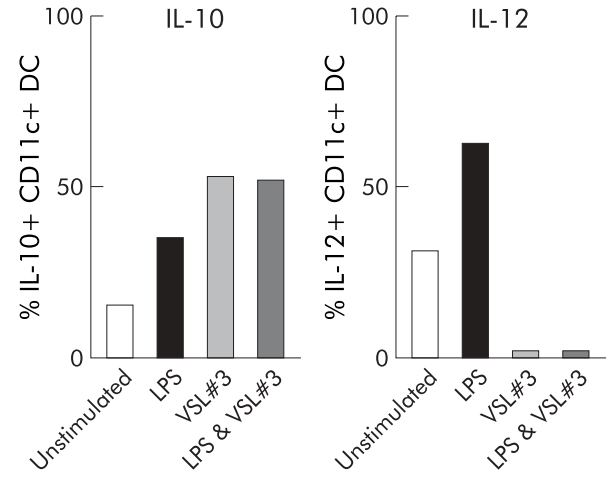

Figure 3 Co-culture of VSL\#3 with LPS decreased the proinflammatory effects of LPS. In whole blood, VSL\#3 at $10^{8} \mathrm{CFU} / \mathrm{ml}$ and LPS at $1 \mu \mathrm{g} / \mathrm{ml}$ were co-cultured and cytokine production assessed by intracellular staining. The proportion of CDI lc+ DC producing IL-10 and IL-12 in these co-cultures is shown. The data shown are representative of three independent experiments.
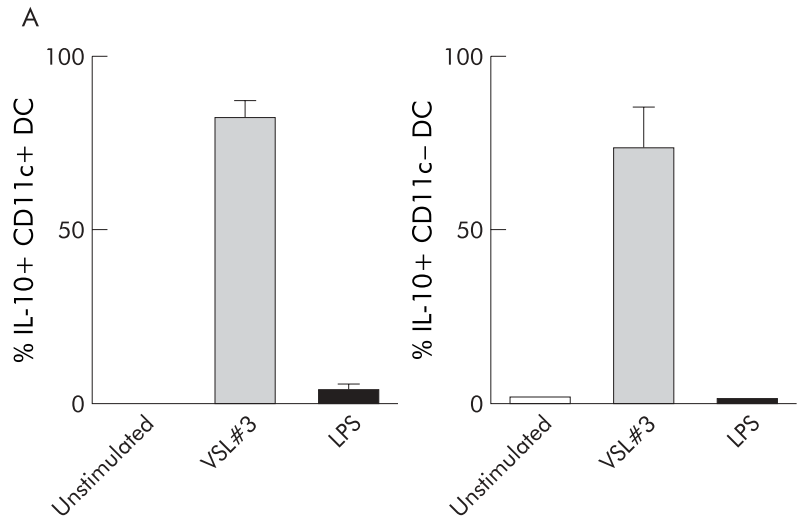

B
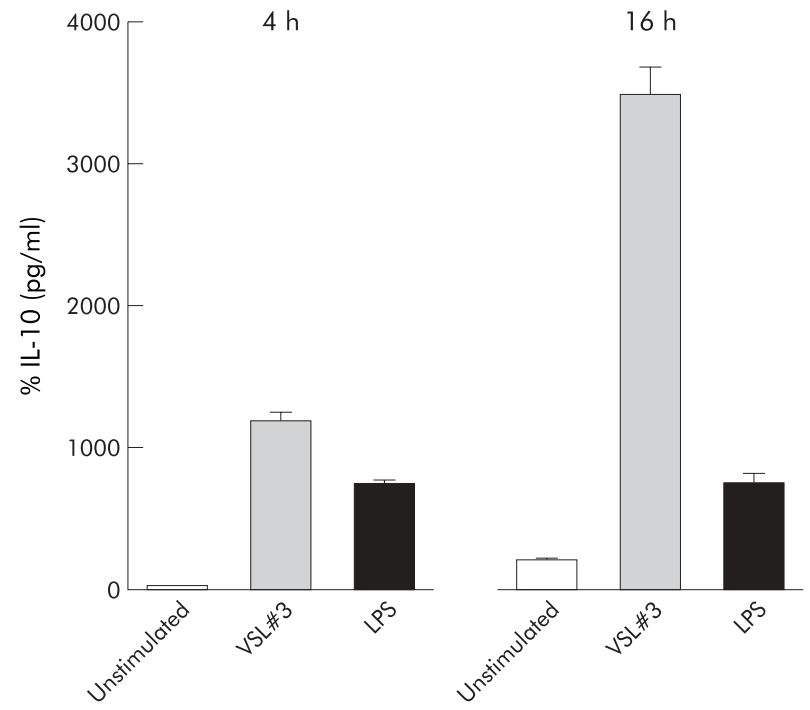

Figure 4 Enhanced IL-10 production by an enriched DC population in the presence of probiotic bacteria (VSL\#3). (A) An enriched DC population (metrizamide separated) was cultured with control medium alone, VSL\#3 probiotic bacteria (at a dose equivalent to $10^{8} \mathrm{CFU} / \mathrm{ml}$ ) or LPS $(1 \mu \mathrm{g} / \mathrm{ml})$ for four hours and the IL-10 production assessed by intracellular cytokine staining. (B) The concentration of IL-10 in the supernatants of enriched DC cultured with control medium, VSL\#3 (at a dose equivalent to $\left.10^{8} \mathrm{CFU} / \mathrm{ml}\right)$ or LPS $(1 \mu \mathrm{g} / \mathrm{ml})$ was measured by ELISA at four hours and 16 hours. The results are representative of three independent experiments. 

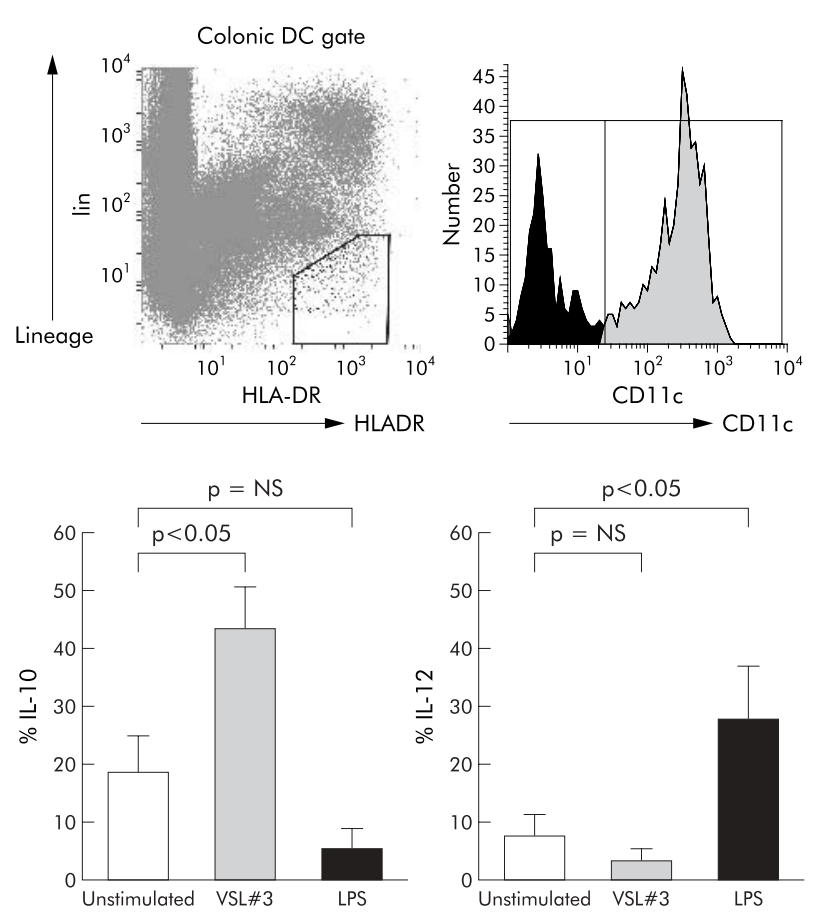

Figure 5 Cytokine production by lamina propria $C D 11 \mathrm{c}+\mathrm{DC}$ extracted from mucosal tissue. DC were identified by multicolour flow cytometry as HLA-DR+ lineage-negative (CD3-, CD14-, CD16-, CD19-, CD34-, and $C D 56-)$. Within this gate, $C D 11 C+D C$ were identified. The effect of control medium alone, VSL\#3 (at a dose equivalent to $\left.10^{8} \mathrm{CFU} / \mathrm{ml}\right)$ or LPS $(1 \mu \mathrm{g} / \mathrm{ml})$ on IL- 10 and IL- 12 production by intestinal derived CDI lc+DC is shown (mean (SEM), $n=9-11$ ).

dose dependent over the range $10^{6}-10^{9} \mathrm{CFU} / \mathrm{ml}$ with maximal IL-10 detected at $10^{8} \mathrm{CFU} / \mathrm{ml}$ (data not shown). In contrast, there was a trend towards enhanced IL- 12 production by DC in the presence of LPS. Co-culture of VSL\#3 at $10^{8} \mathrm{CFU} / \mathrm{ml}$ with LPS at $1 \mu \mathrm{g} / \mathrm{ml}$ significantly diminished the proinflammatory effects of LPS by decreasing IL-12 while maintaining IL-10 production (see fig 3 for representative experiment). In analysis of paired pooled data, addition of VSL\#3 to LPS stimulated cultures significantly reduced the proportion of CDllc+ DC producing IL-12 (42.5 (SEM 9.85) $\%$ for LPS alone $v 0 \%$ for LPS plus VSL\#3; $<<0.05, \mathrm{n}=3$ ). IL-10 production induced by VSL\#3 was not significantly altered by addition of LPS (57 (SEM 3.4) \% IL-10+ CDIlc+ DC for VSL\#3 alone $v 51.3$ (SEM 12.9) \% for VSL\#3 plus LPS; $\mathrm{n}=3$ ).

The enhanced IL-10 production by DC in whole blood with VSL\#3 was confirmed by incubating an enriched DC population with VSL\#3 and assessing IL-10 production by both intracellular cytokine staining (fig 4A) and ELISA (fig 4B).

To determine whether upregulation of IL-10 production by VSL\#3 also occurred with intestinal DC, we examined cytokine production by human colonic LPDC. Intestinal LPDC were identified from lamina propria mononuclear cells as a CDllc+ HLA-DR+ lineage-negative (CD3-, CD14-, CD16-, CD19-, CD34-, CD56-) population (fig 5). This population had the phenotype of immature DC, consistent with our previous findings ${ }^{22}$ A proportion of unstimulated LPDC produced IL-10 (18.6 (SEM 6.5) \%, n= 11) and this IL-10 production was upregulated following incubation with VSL\#3 (44.1 (SEM 7.4) \%, $\mathrm{n}=9$ ). A small proportion of unstimulated LPDC produced IL-12 (8.6 (SEM 3.8) \%, n=6) and this was not upregulated by VSL\#3. In contrast, LPS enhanced the proportion of DC producing IL-12.
Individual bacterial strains differentially modulate IL- 10 and IL- 12 production and expression of costimulatory/maturation markers by dendritic cells Different bacterial strains evoked different cytokine responses when cultured with whole blood (fig 6). All bifidobacteria significantly upregulated IL-10 production by both CDllct and CDllc- DC and this increase in IL-10 was dose dependent over the range of concentrations $10^{6}-10^{8} \mathrm{CFU} / \mathrm{ml}$ (data not shown). In contrast, lactobacilli decreased or had no significant effect on production of IL-10 by both CDllct and CDIlc- DC. Streptococcal strains had no significant effect on IL-10-producing DC.

None of the bacteria tested induced IL-12 production by CDllc+ or CDllc- DC. Some components of VSL\#3, illustrated in figure 6 , significantly inhibited IL-12 production.

VSL\#3 strains differentially modulated DC expression of maturation and costimulatory molecules (table 2). The proportion of DC expressing CD80 was significantly less in cultures stimulated with the bifidobacteria strains than in unstimulated cultures: $B$ infantis and $B$ breve affected both CDllc+ and CDIlc- DC; only CD11c- DC were significantly affected by $B$ longum. In unstimulated cultures the majority of DC expressed CD40. None of the bacterial preparations significantly altered the proportion of CD40+ DC although there was a trend towards a reduction in cultures stimulated with bifidobacteria. Consistent with an effect of bifidobacteria on CD40 expression, analysis of the level of CD40 expressed demonstrated a significantly lower level of CD40 on CDllc+ DC in the presence of $B$ infantis and $B$ breve (data not shown). The proportion of DC expressing CD83 was also high in unstimulated cultures and there was a tendency for all bacterial strains to increase this proportion further, with $L$ casei and $L$ plantarum significantly increasing the level. CD86 was not significantly altered by any of the bacterial strains.

\section{VSL $\# 3$ treatment of dendritic cells inhibits generation of Th 1 cells}

To determine whether the ability of VSL\#3 or its components to increase IL-10 production by DC influenced the subsequent $\mathrm{T}$ cell response, two different assays were performed. Purified naïve CD4+ T cells were activated in the presence of enriched allogeneic DC treated with VSL\#3, LPS, or medium alone and the cytokine profile of the differentiated $\mathrm{T}$ cells was examined. Enriched DC were potent stimulators of allogeneic naïve $\mathrm{CD}^{+} \mathrm{T}$ cells irrespective of pretreament with bacterial products (data not shown). However, significantly fewer $\mathrm{T}$ cells committed to IFN- $\gamma$ production were generated in cultures activated with VSL\#3-treated DC (21.8 (SEM 5.0) \%, $\mathrm{n}=4)$ than in cultures stimulated with LPS treated DC $(42.0$ (SEM 4.1$) \%, \mathrm{n}=4$ ) or unstimulated DC (36.3 (SEM 5.0) \%, $\mathrm{n}=4$ ) (fig 7). The proportion of differentiated T cells making IL-10 or IL-4 did not differ significantly between the cultures.

In addition, single probiotic strains were incubated with whole blood and the effect on IFN- $\gamma$ production by CD8+ and CD8- T cells was assessed after polyclonal stimulation with PMA and ionomycin. Prior exposure to $B$ longum and $B$ infantis, but not the other bacteria tested, significantly reduced the proportion and absolute numbers of CD8$\mathrm{T}$ cells and CD8+ T cells producing IFN $-\gamma$ in a dose dependent manner (fig 8). Compared with medium control, the proportion of CD8 - T cells producing IFN- $\gamma$ was reduced by $46 \%$ with $B$ longum ( $\mathrm{n}=9$ independent experiments) and $62 \%$ with $B$ infantis ( $\mathrm{n}=9$ independent experiments); the proportion of CD8+ T cells producing IFN- $\gamma$ was reduced by $50 \%$ (B longum) and $61 \%$ (B infantis). The effects of bacterial debris fractions on IFN- $\gamma$ production were selective for cytokine production, rather than a reflection of reduced $\mathrm{T}$ cell activation or a toxic effect of the bacterial preparation, 

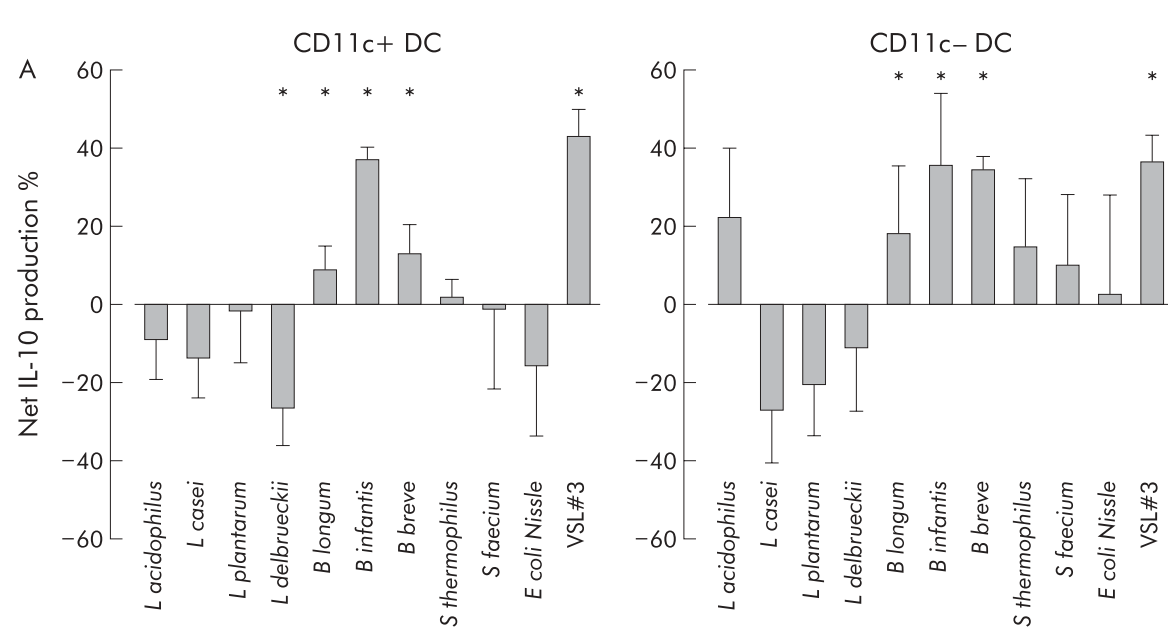

Figure 6 Effect of individual bacterial strains on IL-12 and IL-10 production by CDI lct and CDIlc- DC. When addition of bacteria to the culture increased cytokine production compared with that seen in the absence of any added stimulus for a given individual, the proportion of cytokine producing cells was taken as a net positive value. If the bacteria decreased cytokine production compared with that seen in the absence of bacteria, the proportion and absolute number of cells was taken as a net negative value. The data indicate the mean (SEM) for three to six independent experiments. (A) The effect of the different probiotic strains at $10^{8} \mathrm{CFU} / \mathrm{ml}$ on IL-10 production by CDIlc+ and CDIlc- DC. (B) The effect of the different probiotic strains at $10^{8} \mathrm{CFU} / \mathrm{ml}$ on IL-12 production by CDI lc+ and CDI lc-DC. * Significant
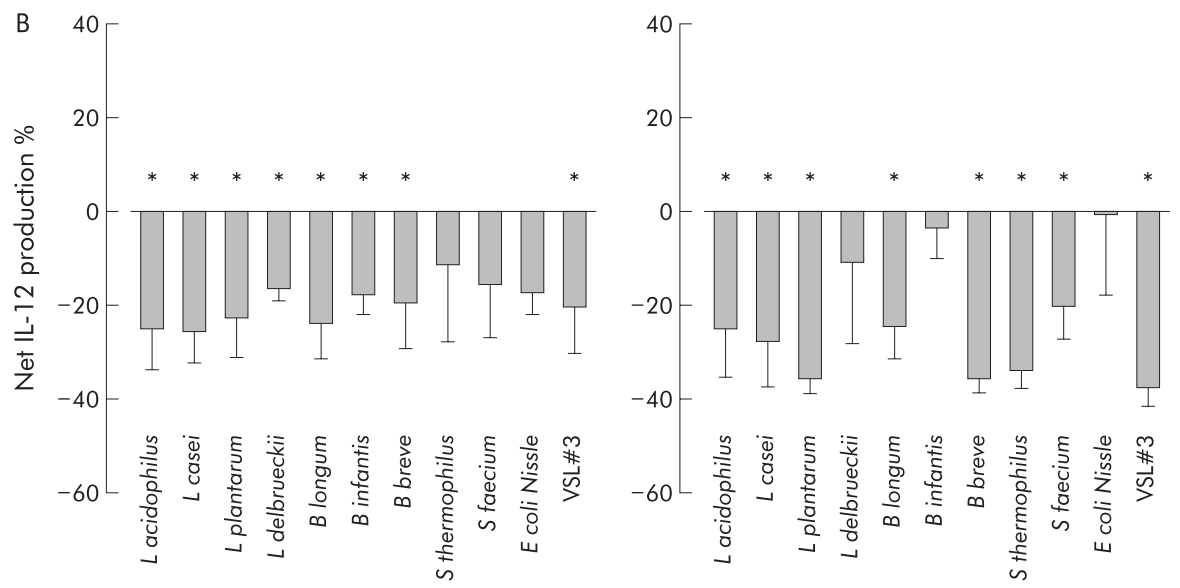
changes in cytokine production in the presence of the bacterial stimuli.

as over 97\% were activated (CD69+) by PMA and ionomycin irrespective of prior exposure to bacteria (data not shown). To assess whether the decrease in IFN $-\gamma$ by $\mathrm{T}$ cells was dependent on IL-10, a neutralising anti-IL-10 blocking antibody was added to some cultures. For both CD8+ and CD8$\mathrm{T}$ cells, the inhibition of IFN $-\gamma$ production by $B$ longum was reversed significantly by a neutralising anti-IL-10 antibody, but not an isotype matched control. Anti-IL-10 reversed the

Table 2 Effect of individual bacterial strains on costimulatory and maturation markers

\begin{tabular}{|c|c|c|c|c|}
\hline & \multicolumn{4}{|c|}{$\%$ Positive dendritic cells } \\
\hline & \multicolumn{2}{|l|}{ CD80 } & \multicolumn{2}{|l|}{ CD40 } \\
\hline & $C D 11 c+D C$ & $C D 11 c-D C$ & $C D 11 c+D C$ & CDIlc- DC \\
\hline Control & $13(2)$ & $35(10)$ & $78(2)$ & $61(9)$ \\
\hline L acidophilus & $19(10)$ & $27(8)$ & 79 (3) & $82(3)$ \\
\hline L casei & 31 (8) & $31(7)$ & $78(3)$ & $83(4)$ \\
\hline L plantarum & $28(9)$ & $29(5)$ & $78(4)$ & $85(2)$ \\
\hline L bulgaricus & 38 (13) & $30(6)$ & 79 (3) & $83(4)$ \\
\hline$B$ longum & $7(5)$ & $0(0)^{*}$ & $71(5)$ & $60(7)$ \\
\hline$B$ infantis & $6(4)^{*}$ & $3(2)^{*}$ & 65 (13) & $63(6)$ \\
\hline B breve & $2(1)^{*}$ & $0(0)^{*}$ & 44 (12) & $59(3)$ \\
\hline S thermophilus & $23(7)$ & $18(8)$ & $75(3)$ & $81(3)$ \\
\hline$S$ faecium & $9(5)$ & $2 \pm^{*}$ & 69 (9) & $69(5)$ \\
\hline E coli Nissle & $26(14)$ & $13(9)$ & $83(5)$ & $85(4)$ \\
\hline LPS & $13(2)$ & $43(8)$ & $86(4)$ & $89(5)$ \\
\hline
\end{tabular}

inhibition of IFN- $\gamma$ production by B infantis for CD8- T cells only. (fig 8).

\section{DISCUSSION}

The clinically active probiotic combination VSL\#3 was a potent inducer of IL-10 by intestinal and blood DC and inhibited generation of proinflammatory Thl cells. Individual strains within VSL\#3 displayed distinct and diverse immunomodulatory effects. The most marked anti-inflammatory effect was shown by bifidobacterial species which upregulated IL-10 production by DC and decreased expression of the costimulatory molecules CD80 and CD40. These effects of probiotic bacteria on DC may underlie their antiinflammatory activity.

The individual bacteria in VSL\#3 displayed different effects on cytokine production by DC, arguing against a common bacterial component such as peptidoglycan mediating the effects. Differences between strains have been reported previously; $B$ bifidum, $B$ breve, and $B$ infantis stimulated more IL-10 and less IL-12 and TNF $\alpha$ from a murine macrophage like cell line than $B$ adolescentis. ${ }^{25}$ Moreover, there was no simple correlation between reported DC expression of TLR and responses to VSL\#3. Thus responses of CDllc+ and CDllc- DC subsets to VSL\#3 were broadly similar although these two populations express a different array of the known TLRs. ${ }^{26}$ The divergent patterns of responses to VSL\#3 and expression of TLRs suggests that other receptors may be involved in DC recognition of VSL\#3 or that recognition of VSL\#3 components by TLRs on non-DC may contribute. 


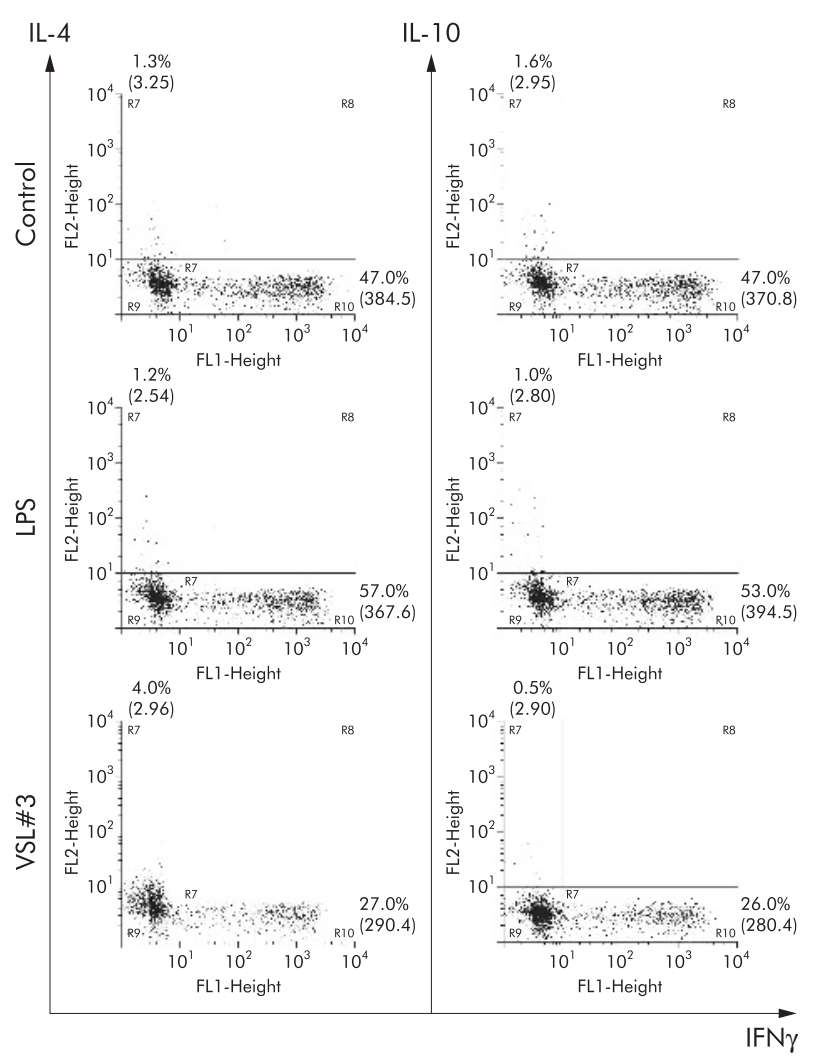

Figure 7 Probiotic bacteria (VSL\#3) inhibit the generation of IFN $\gamma$ producing T cells. Naiive T cells and enriched DC treated with control medium, VSL\#3 (at a dose equivalent to $10^{8} \mathrm{CFU} / \mathrm{ml}$ ) or LPS $(1 \mu \mathrm{g} / \mathrm{ml})$ were co-cultured. Cells were restimulated with PMA and ionomycin and cytokine production was assessed by intracellular cytokine staining Staining for IFN- $\gamma$, IL-4, and IL-10 is shown. The proportion of cells and the geometric mean of fluorescence intensity are represented. Results are representative of four independent experiments.

Intestinal DC are functionally different from those at other sites. $^{3627}$ In vitro, VSL\#3 increased the proportion not only of blood DC making IL-10 but also of colonic lamina propria DC making IL-10, suggesting that one mechanism of action of VSL\#3 in vivo is to trigger DC production of antiinflammatory IL-10 in intestinal mucosa. Patients with pouchitis taking VSL\#3 have increased mucosal levels of
IL-10 and decreased levels of IFN- $\gamma^{28}$ and in murine colitis, proinflammatory TNF- $\alpha$ and IFN- $\gamma$ are decreased following treatment with VSL\#3. ${ }^{29}$ Enhanced production of IL-10 by DC may limit mucosal inflammation either by direct antiinflammatory effects or by enhancing the generation or activity of regulatory $\mathrm{T}$ cells $(\mathrm{Tr} \mathrm{l})$. In experimental colitis, local administration of IL-10 in bacterial $^{30}$ or viral ${ }^{31}$ vectors ameliorates inflammation. Adoptive transfer of regulatory $\mathrm{T}$ cells cures or prevents intestinal inflammation in murine colitis by IL-10 dependant mechanisms. ${ }^{32-34}$ In another mucosal environment in the lung, high concentrations of IL-10 produced by pulmonary DC are associated with the generation of regulatory $\mathrm{T}$ cells. ${ }^{2}$

Bacteria may differentially alter antigen presentation and the level of DC activation. Bifidobacteria generally downregulated the proportion of DC expressing CD80 but not the proportion of those expressing CD86. This differential effect between members of the B7 family of costimulatory molecules may be related to the difference in proportions of DC expressing CD80 and CD86 in unstimulated cultures. Confirming other work, ${ }^{35}$ we found more DC expressing CD86 than CD80 in the absence of stimulation. Thus, CD80 expression may be more readily modulated through environmental signals. Both CD80 and CD86 bind to CD28 and CD152 (CTLA4) on T cells. It remains controversial whether they have distinct functions, ${ }^{36}$ but relative amounts of CD80 and CD86 on antigen presenting cells may influence the type of $\mathrm{T}$ cell response generated.

Effects of bifidobacteria were not confined to CD80 and CD86. $B$ breve and $B$ infantis reduced the level of CD40 expression on DC. Signalling through CD40 increases IL-12 production by DC and enhances their survival. ${ }^{37}{ }^{38}$ Increased levels of expression of CD40 on $\mathrm{DC}^{39}$ and its ligand, CD154, on $\mathrm{T}$ cells $^{40}$ in IBD tissue suggests that this interaction is important in mucosal inflammation. VSL\#3 treatment of IBD may mediate downregulation of CD40 expression, breaking the inflammatory cycle of mutual T cell-DC stimulation.

In contrast to bifidobacteria, lactobacilli appeared to generate "semi-mature" $\mathrm{DC}^{41}$ a phenotype characterised by increased costimulatory marker expression but low production of proinflammatory cytokines. Such "semi-mature" DC may contribute to the production of regulatory $\mathrm{T}$ cells and subsequent tolerance in vivo. ${ }^{41}$

VSL\#3 inhibited T cell production of IFN- $\gamma$ in two different systems. This reduction in proinflammatory cytokine production was not accompanied by an obvious increase in either IL-4-producing or IL-10-producing T cells arguing against a
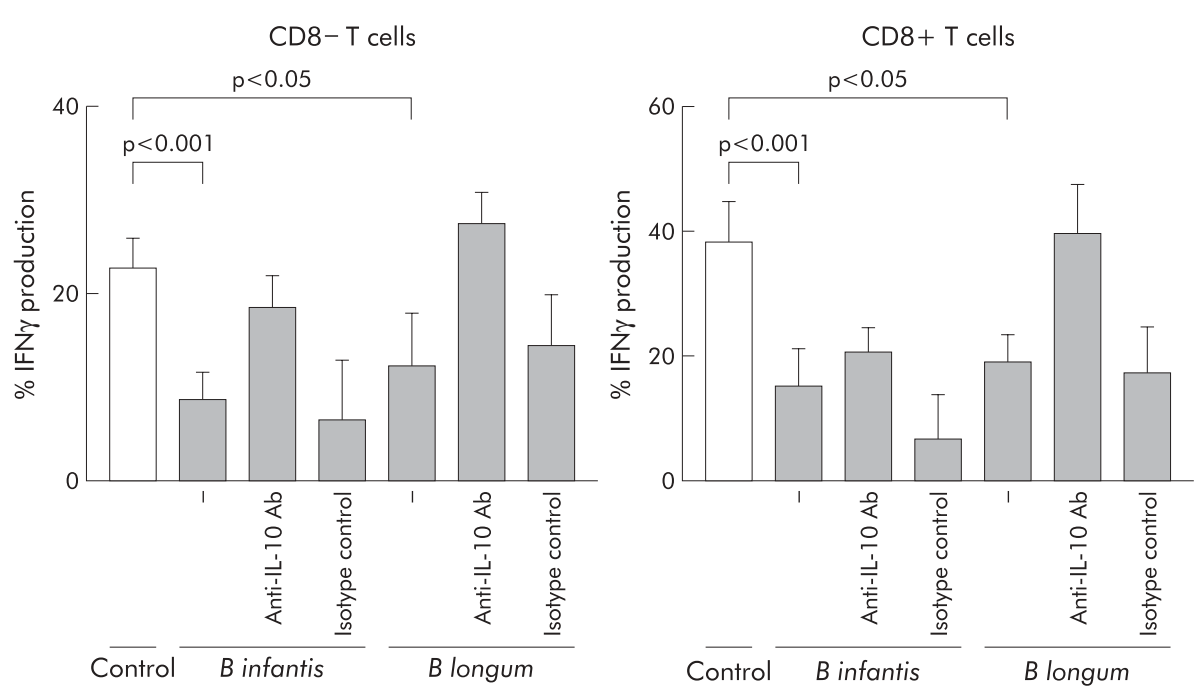

Figure 8 Individual probiotic strains decrease IFN- $\gamma$ production by polyclonally stimulated T cells. Individual probiotic strains at $10^{8} \mathrm{CFU} /$ $\mathrm{ml}$ were incubated with whole blood. Subsequently the cultures were stimulated with PMA and ionomycin and the effect of preculturing with the probiotic strain on cytokine production was observed. In some cultures an antiIL-10 neutralising antibody or its isotype control were added and the effect on IFN- $\gamma$ assessed. Results indicate the mean (SEM) of at least nine experiments. 
simple model in which VSL\#3 induces a switch from Thl to Th2 production. On the basis of the current data, its is not possible to determine whether the effect of VSL\#3 treated DC acts at the level of $\mathrm{T}$ cell instruction or whether it operates by selection and expansion of different $\mathrm{T}$ cell precursors. DC stimulated comparable proliferative responses irrespective of bacterial treatment, suggesting that a major effect on lymphocyte viability is unlikely. IL-10 may contribute to the effect on T cells because neutralising IL-10 partially reversed VSL\#3 mediated downregulation of IFN $\gamma$.

In conclusion, VSL\#3, which is clinically beneficial in the treatment of intestinal inflammation, changes the cytokines in DC from an inflammatory towards a regulatory profile, which may be instrumental in the immunomodulatory activity of probiotic treatments. An increased understanding of the effects of probiotic organisms on the immune system may enable refinement of probiotic treatments and enhance our knowledge of immune homeostasis in the specialised environment of the intestine.

\section{ACKNOWLEDGEMENTS}

This work was supported by grants from the Wellcome Trust and Medical Research Council (UK).

\section{Authors' affiliations}

A L Hart, S C Knight, A J Stagg, Antigen Presentation Research Group, Imperial College London, Harrow, UK

K Lammers, F Rizzello, P Gionchetti, M Campieri, Department of Internal Medicine and Gastroenterology, University of Bologna, Bologna, Italy

P Brigidi, B Vitali, Department of Pharmaceutical Sciences, University of Bologna, Bologna, Italy

M A Kamm, Department of Gastroenterology, St Mark's Hospital, Harrow, UK

\section{REFERENCES}

1 Stagg AJ, Hart AL, Knight SC, et al. The dendritic cell: its role in intestinal inflammation and relationship with gut bacteria. Gut 2003:52:1522-9.

2 Akbari O, DeKruyff RH, Umetsu DT. Pulmonary dendritic cells producing IL-10 mediate tolerance induced by respiratory exposure to antigen. Nat Immunol $2001 ; 2: 725-31$

3 Iwasaki A, Kelsall BL. Freshly isolated Peyer's patch, but not spleen, dendritic cells produce interleukin 10 and induce the differentiation of Thelper type 2 cells. J Exp Med 1999; 190:229-39.

4 Williamson E, Bilsborough JM, Viney JL. Regulation of mucosal dendritic cell function by receptor activator of NF-kappa B (RANK)/RANK ligand interactions: impact on tolerance induction. J Immunol 2002;169:3606-12.

5 Viney JL, Mowat AM, O'Malley JM, et al. Expanding dendritic cells in vivo enhances the induction of oral tolerance. J Immunol 1998;160:5815-25.

6 Stagg AJ, Kamm MA, Knight SC. Intestinal dendritic cells increase T cell expression of alpha4beta7 integrin. Eur J Immunol 2002;32:1445-54.

7 Rescigno M, Urbano M, Valzasina B, et al. Dendritic cells express tight junction proteins and penetrate gut epithelial monolayers to sample bacteria. Nat Immunol $2001 ; 2: 361-7$

8 Christensen HR, Frokiaer H, Pestka JJ. Lactobacilli differentially modulate expression of cytokines and maturation surface markers in murine dendritic cells. J Immunol 2002;168:171-8.

9 d'Ostiani CF, Del Sero G, Bacci A, et al. Dendritic cells discriminate between yeasts and hyphae of the fungus Candida albicans. Implications for initiation of T helper cell immunity in vitro and in vivo. J Exp Med 2000;191:1661-74.

10 Palma JP, Yauch RL, Kang HK, et al. Preferential induction of IL-10 in APC correlates with a switch from Th1 to Th2 response following infection with a low pathogenic variant of Theiler's virus. J Immunol 2002;168:4221-30.

11 Pulendran B, Kumar P, Cutler CW, et al. Lipopolysaccharides from distinct pathogens induce different classes of immune responses in vivo. J Immunol 2001:167:5067-76.

12 Hirschfeld M, Weis JJ, Toshchakov V, et al. Signaling by toll-like receptor 2 and 4 agonists results in differential gene expression in murine macrophages. Infect Immun $2001 ; 69: 1477-82$.

13 Banchereau J, Steinman RM. Dendritic cells and the control of immunity. Nature 1998;392:245-52.
14 Steinman RM, Nussenzweig MC. Avoiding horror autotoxicus: the importance of dendritic cells in peripheral T cell tolerance. Proc Natl Acad Sci USA 2002;99:351-8.

15 Macatonia SE, Hosken NA, Litton M et al. Dendritic cells produce IL-12 and direct the development of Th1 cells from naive CD4+ T cells. J Immunol 1995; 154:5071-9.

16 Kelleher P, Maroof A, Knight SC. Retrovirally induced switch from production of IL-12 to IL-4 in dendritic cells. Eur J Immunol 1999:29:2309-18.

17 Gionchetti P, Rizzello F, Venturi A, et al. Oral bacteriotherapy as maintenance treatment in patients with chronic pouchitis: a double-blind, placebocontrolled trial. Gastroenterology 2000;1 19:305-9.

18 Gionchetti P, Rizzello F, Helwig U, et al. Prophylaxis of pouchitis onset with probiotic therapy: a double-blind, placebo-controlled trial. Gastroenterology 2003; 124:1202-9.

19 Kruis W, Schutz E, Fric P, et al. Double-blind comparison of an oral Escherichia coli preparation and mesalazine in maintaining remission of ulcerative colitis. Aliment Pharmacol Ther 1997;1 1:853-8.

20 Rembacken BJ, Snelling AM, Hawkey PM, et al. Non-pathogenic Escherichia coli versus mesalazine for the treatment of ulcerative colitis: a randomised trial. Lancet 1999:354:635-9.

21 Lammers KM, Helwig U, Swennen E, et al. Effect of probiotic strains on interleukin 8 production by HT29/19A cells. Am J Gastroenterol 2002;97:1 182-6

22 Bell SJ, Rigby R, English N, et al. Migration and maturation of human colonic dendritic cells. J Immunol 2001;166:4958-67.

23 North ME, Ivory K, Funauchi M, et al. Intracellular cytokine production by human CD4+ and CD8+ T cells from normal and immunodeficient donors using directly conjugated anti-cytokine antibodies and three-colour flow cytometry. Clin Exp Immunol 1996; 105:517-22.

24 Panoskaltsis N, Reid CD, Knight SC. Quantification and cytokine production of circulating lymphoid and myeloid cells in acute myelogenous leukaemia. Leukemia 2003;17:716-30.

$25 \mathrm{He} \mathrm{F}$, Morita H, Ouwehand AC, et al. Stimulation of the secretion of proinflammatory cytokines by Bifidobacterium strains. Microbiol Immunol 2002;46:781-5.

26 Kadowaki N, Ho S, Antonenko S, et al. Subsets of human dendritic cell precursors express different toll-like receptors and respond to different microbial antigens. J Exp Med 2001;194:863-9.

27 Powell TJ, Jenkins CD, Hattori R, et al. Rat bone marrow-derived dendritic cells, but not ex vivo dendritic cells, secrete nitric oxide and can inhibit T-cell proliferation. Immunology 2003;109:197-208.

28 Ulisse S, Gionchetti P, D'Alo S, et al. Expression of cytokines, inducible nitric oxide synthase, and matrix metalloproteinases in pouchitis: effects of probiotic treatment. Am J Gastroenterol 2001:96:2691-9.

29 Madsen K, Cornish A, Soper P, et al. Probiotic bacteria enhance murine and human intestinal epithelial barrier function. Gastroenterology 2001;121:580-91.

30 Steidler L, Hans W, Schotte L, et al. Treatment of murine colitis by Lactococcus lactis secreting interleukin-10. Science 2000;289:1352-5.

31 Lindsay JO, Ciesielski CJ, Scheinin T, et al. The prevention and treatment of murine colitis using gene therapy with adenoviral vectors encoding IL-10. $\mathrm{J}$ Immunol 2001;166:7625-33.

32 Powrie F, Leach MW, Mauze S, et al. Inhibition of Th1 responses prevents inflammatory bowel disease in scid mice reconstituted with CD45RBhi CD4+ T cells. Immunity 1994; 1:553-62.

33 Asseman C, Mauze S, Leach MW, et al. An essential role for interleukin 10 in the function of regulatory $T$ cells that inhibit intestinal inflammation. J Exp Med 1999;190:995-1004.

34 Groux H, O'Garra A, Bigler M, et al. A CD4+ T-cell subset inhibits antigenspecific T-cell responses and prevents colitis. Nature 1997;389:737-42.

35 McLellan AD, Starling GC, Williams LA, et al. Activation of human peripheral blood dendritic cells induces the CD86 co-stimulatory molecule. Eur J Immunol 1995;25:2064-8.

36 Sansom DM, Manzotti CN, Zheng Y. What's the difference between CD80 and CD86? Trends Immunol 2003;24:314-19.

37 Biorck P, Banchereau J, Flores-Romo L. CD40 ligation counteracts Fasinduced apoptosis of human dendritic cells. Int Immunol 1997;9:365-72.

38 Cella M, Scheidegger D, Palmer-Lehmann K, et al. Ligation of CD40 on dendritic cells triggers production of high levels of interleukin-12 and enhances T cell stimulatory capacity: T-T help via APC activation. J Exp Med 1996; 184:747-52.

39 Stagg AJ, Bell SJ, Rigby R, et al. Treatment with anti-TNFalpha antibody reduces expression of CD40 on lamina propria dendritic cells. Gastroenterology 2000;118:A353.

40 Liu Z, Colpaert S, D'Haens GR, et al. Hyperexpression of CD40 ligand (CD154) in inflammatory bowel disease and its contribution to pathogenic cytokine production. J Immunol 1999;163:4049-57.

41 Lutz MB, Schuler G. Immature, semi-mature and fully mature dendritic cells: which signals induce tolerance or immunity? Trends Immunol 2002;23:445-9. 